12-1-2009

\title{
Fuzzy Logic in neurosurgery: Predicting poor outcomes after lumbar disk surgery in 501 consecutive patients
}

Muhammad Shahzad Shamim

Aga Khan University, shahzad.shamim@aku.edu

Ather Enam

Aga Khan University, ather.enam@aku.edu

Uvais Qidwai

Qatar University, Qatar

Follow this and additional works at: https://ecommons.aku.edu/pakistan_fhs_mc_surg_neurosurg

Part of the Neurology Commons, Neurosurgery Commons, and the Surgery Commons

\section{Recommended Citation}

Shamim, M., Enam, A., Qidwai, U. (2009). Fuzzy Logic in neurosurgery: Predicting poor outcomes after lumbar disk surgery in 501 consecutive patients. Surgical Neurology, 72(6), 565-572.

Available at: https://ecommons.aku.edu/pakistan_fhs_mc_surg_neurosurg/22 
Spine

\title{
Fuzzy Logic in neurosurgery: predicting poor outcomes after lumbar disk surgery in 501 consecutive patients
}

\author{
Muhammad Shahzad Shamim, MBBS, MCPS, MRCS (Glasgow), FCPS (Neurosurgery), \\ Syed Ather Enam, MBBS, MD, PhD, FRCS (Ire), FRCS (SN, CAN), DABS, FACS ${ }^{\text {a,*, }}$ \\ Uvais Qidwai, BE, ME, $\mathrm{PhD}^{\mathrm{b}}$ \\ ${ }^{a}$ Section of Neurosurgery, Department of Surgery, Aga Khan University Hospital, P.O. Box 3500, Stadium Road, Karachi 74800, Pakistan \\ ${ }^{\mathrm{b}}$ Department of Computer Science and Engineering, Qatar University, Qatar \\ Received 13 February 2009; accepted 2 July 2009
}

Abstract

\begin{abstract}
Background: Despite a lot of research into patient selection, a significant number of patients fail to benefit from surgery for symptomatic lumbar disk herniation. We have used Fuzzy Logic-based fuzzy inference system (FIS) for identifying patients unlikely to improve after disk surgery and explored FIS as a tool for surgical outcome prediction.

Methods: Data of 501 patients were retrospectively reviewed for 54 independent variables. Sixteen variables were short-listed based on heuristics and were further classified into memberships with degrees of membership within each. A set of 11 rules was formed, and the rule base used individual membership degrees and their values mapped from the membership functions to perform Boolean Logical inference for a particular set of inputs. For each rule, a decision bar was generated that, when combined with the other rules in a similar way, constituted a decision surface. The FIS decisions were then based on calculating the centroid for the resulting decision surfaces and thresholding of actual centroid values. The results of FIS were then compared with eventual postoperative patient outcomes based on clinical follow-ups at 6 months to evaluate FIS as a predictor of poor outcome. Results: Fuzzy inference system has a sensitivity of $88 \%$ and specificity of $86 \%$ in the prediction of patients most likely to have poor outcome after lumbosacral miscrodiskectomy. The test thus has a positive predictive value of 0.36 and a negative predictive value of 0.98 .

Conclusion: Fuzzy inference system is a sensitive method of predicting patients who will fail to improve with surgical intervention.
\end{abstract}

(C) 2009 Elsevier Inc. All rights reserved.

Keywords:

Disk herniation; Microdiskectomy; Outcome prediction

\section{Introduction}

Microdiskectomy for intervertebral disk herniations is among the commonest neurosurgical procedures with good to excellent outcomes reported in up to $90 \%$ of patients;

Abbreviations: FDS, failed disk surgery; FIS, fuzzy inference system; TMF, triangular membership functions.

* Corresponding author. Tel.: +92 21486 4710x4764.

E-mail addresses: shahzad.shamim@aku.edu (M.S. Shamim), ather.enam@aku.edu (S.A. Enam), uqidwai@gmail.com (U. Qidwai). however, despite better understanding of pathologic condition, improvements in radiologic imaging, and microsurgical techniques, a proportion of patients still fail to improve after disk surgeries that according to different researchers vary from $20 \%$ to $40 \%$ of patients $[1,4,8,10,15,16,28,33,34,57,63]$. A number of techniques have been tried to predict this group of patients including psychosomatic scoring systems and others [11-13,25,32,41,56,61]. We have reviewed our own results with 501 consecutive lumbar microdiskectomies and have applied Fuzzy Logic-based fuzzy inference system (FIS) 
retrospectively on 54 different patient-related independent variables, validating it with their eventual postoperative outcomes, so as to establish whether this method can effectively predict patients most likely to have poor outcomes after disk surgery.

\section{Materials and methods}

\subsection{Data collection}

The study was conducted at the Aga Khan University Hospital (Karachi, Pakistan) using medical records of patients operated from January 2001 to January 2006-a total duration of 5 years. We studied 501 consecutive patients who underwent single or multiple level posterior microdiskectomy for lumbosacral intervertebral disk herniations after at least 8 weeks of conservative management. Patients with concomitant spinal or foraminal stenosis who underwent decompressive procedures other than diskectomy and patients who underwent fusion were excluded from the study. Data were collected on a standardized 2-page proforma having section for patient's demographics, presenting features, physical examination, radiographic information, details of presurgical conservative management, surgical procedure, postoperative course, and follow-ups. A total of 54 independent variables identified from literature that might influence the outcome of surgery were hence collected and computed on Statistical Package for Social Sciences (SPSS) version 13.0 (SPSS Inc, Chicago, Ill). For the purpose of our study, we considered any patient showing no postoperative improvement or worsening in preoperative symptoms to have had a poor outcome (Table 1). We chose to call this condition failed disk surgery as opposed to the widely accepted term of failed back surgery because we only included patients who underwent diskectomy as the procedure to decompress the nerve. All patients with "failed disk surgery" were grouped under the variable "FDS," which was the only dependent variable.

\subsection{Application of FIS}

The 54 variables served as a master list, and out of these variables, the coinvestigator (SAE) short-listed 16 independent variables that he considered important risk factors for FDS (Table 2). Some of these variables are known risk factors for FDS; others were selected based entirely on the coinvestigator's 17 years of clinical experience in neurosurgery. Selection bias was controlled as the coinvestigator was

Table 1

Improvement with surgery

\begin{tabular}{lcccc}
\hline & None & Some & Complete & Worsening \\
\hline $\mathrm{n}$ & 37 & 99 & 360 & 5 \\
$\%$ & 7 & 20 & 72 & 1 \\
\hline
\end{tabular}

Shaded boxes indicates "FDS."
Table 2

Input Memberships

\begin{tabular}{|c|c|c|}
\hline Gender & $\begin{array}{l}\text { Epidural steroid } \\
\text { injection }\end{array}$ & $\begin{array}{l}\text { Duration of } \\
\text { nonoperative } \\
\text { treatment }\end{array}$ \\
\hline Body mass index & $\begin{array}{l}\text { Intraoperative } \\
\text { complications }\end{array}$ & $\begin{array}{l}\text { Emergency or } \\
\text { elective surgery }\end{array}$ \\
\hline Occupation type & Operating surgeon & Operative time \\
\hline Marital status & Duration of symptoms & $\begin{array}{l}\text { Post op } \\
\text { complications }\end{array}$ \\
\hline Oral steroids & $\begin{array}{l}\text { Site, extent of disc } \\
\text { on MRI }\end{array}$ & - \\
\hline Multilevel disease & Previous spine surgery & - \\
\hline
\end{tabular}

blinded to the results of audit. These 16 variables or "inputs" served as the template for all further analysis and were classified further into memberships with 3 degrees of membership within each one of them. The degrees were also assigned based on the heuristics of SAE and were grouped as they were relatively graded with respect to its association within that membership. For instance, if SAE considered duration of symptoms as a significant predictor of FDS, "duration of symptoms" would be considered an "input." For this particular input membership, the degrees were "short," "medium," and "long" and were analyzed as such (it may be noticed here that the investigator was not asked to define short, medium, or long). As stated earlier, the selection of these degrees is entirely dependent upon the heuristics of the physicians. Thus, for any new input value, a particular membership degree will be assigned with an underlying mapping value from its membership function graph (a set of triangular functions). A set of 11 rules was thus formed based entirely on physician's heuristics. This rule base used the membership degrees and their underlying values mapped from the membership functions to perform Boolean Logical inference for a particular set of inputs. For each rule, a decision bar was generated that, when combined with the other rules in a similar way, constituted a decision surface. The actual values of the features were calculated using custom routines written in Matlab version 7 (The MathWorks, Inc, Natick, MA, USA) and provided a range of values for each parameter for each class. The output variable correspond to the FDS risk class for which 3 evenly distributed triangular distributions memberships were selected corresponding to "very low risk," "low risk," and "high risk." The triangular membership functions (TMF) were then used with 3 memberships defined as very low risk, low risk, and high risk depending upon the risk of developing postoperative FDS. The memberships were defined as very low risk, if full TMF was between $-40 \%$ and $40 \%$ with center based at $0 \%$; low risk," if full TMF was between $10 \%$ and $90 \%$ with center based at $50 \%$; and high risk, if full TMF was between $60 \%$ and $140 \%$ with center based at $100 \%$.

The FIS decisions were based on 2 steps: $(a)$ calculating the centroid for the resulting decision surfaces and $(b)$ 


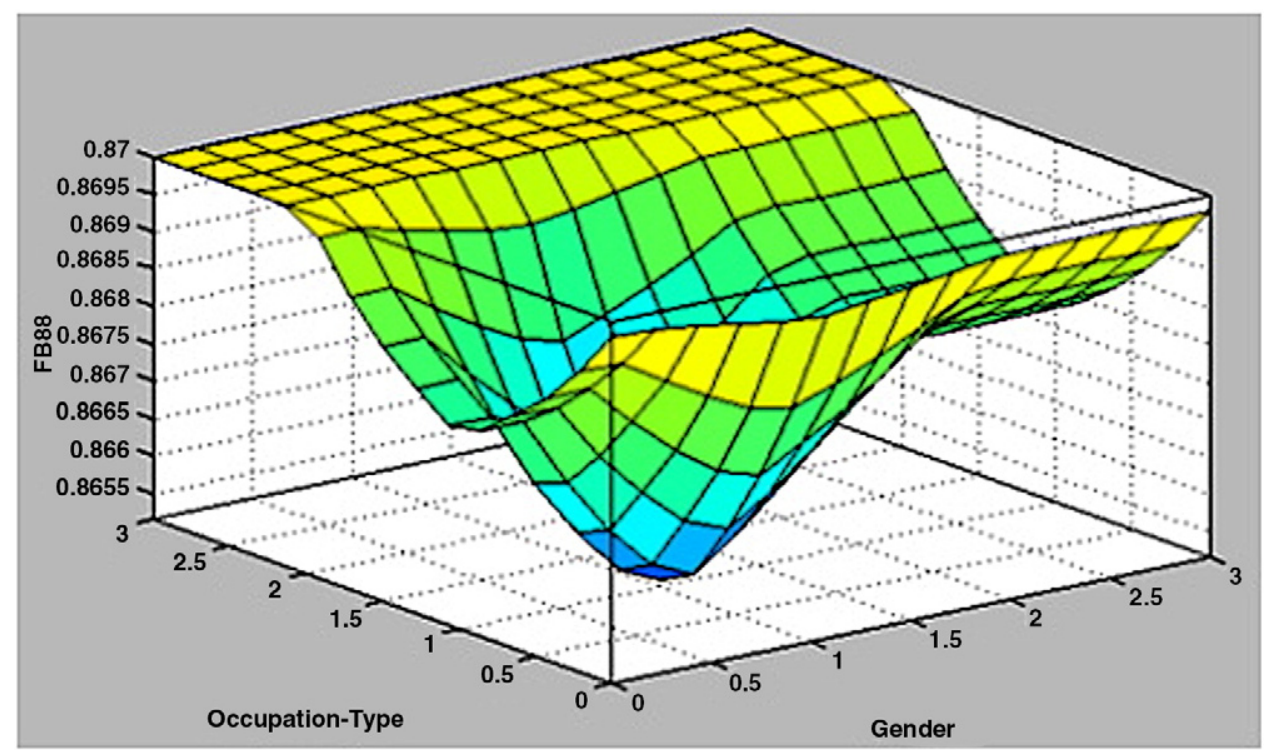

Fig. 1. Example of subset decision surfaces.

thresholding of actual centroid values above 0.6 to 1 . This corresponded to the actual dataset convention where 1 was used to represent the high-risk FDS cases. The results of FIS were then compared with eventual postoperative patient outcomes based on clinical follow-ups. This was done at mean follow-up of 6 months to calculate the sensitivity and specificity of FIS as a predictor of FDS. The resulting decision surfaces are $16 \times 16$ dimensional and cannot be displayed as one hypersurface; however, some subset decision surfaces can be plotted and are shown in Figs. 1 and 2.

\section{Results}

\subsection{Patient profile}

Mean age of our patients was 41 years that is also the mean age reported in most of the literature. There were 345 male patients $(69 \%)$ and 146 female patients $(31 \%)$ - a difference in proportion previously unreported. Mean body mass index of our patients was 26 and was significantly higher in the female patient group. Various details about our patient population are mentioned in Table 2. Of our patients, $96 \%$ had good functional status preoperatively. Fifty-one

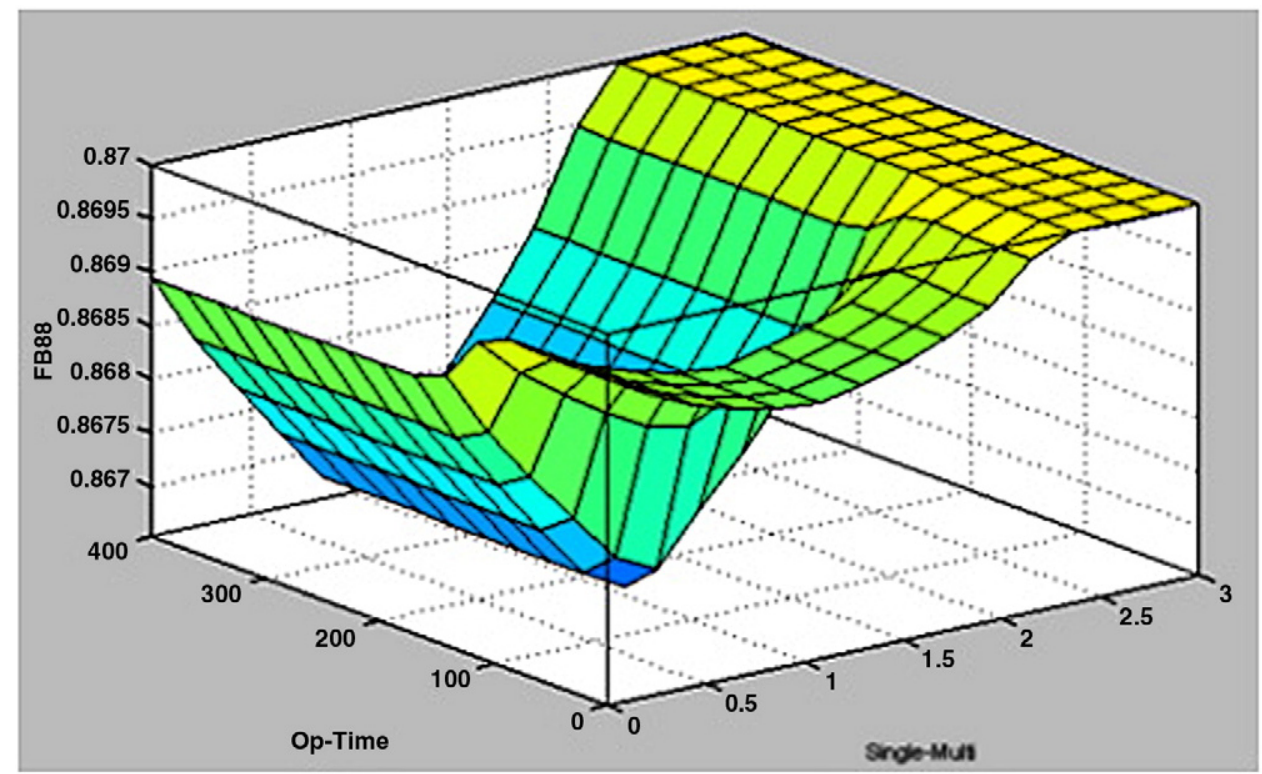

Fig. 2. Example of subset decision surfaces. 
Table 3

Result of FIS-based predictions

\begin{tabular}{lllll}
\hline & & True & False & \\
\hline FIS' predicted outcome & $\begin{array}{l}\text { Actual positive } \\
\text { (FDS/bad outcome patients), 42 } \\
\text { Actual negative } \\
\text { (good outcome patients), 459 }\end{array}$ & True-positive, 37 & False-positive, 65 & Positive predictive value, 0.36 \\
& False-negative, 5 & True-negative, 394 & Negative predictive value, 0.98 \\
\hline
\end{tabular}

$(10 \%)$ of our patients have had previous surgery to their spine. The mean duration of symptoms was 400 days although $80 \%$ of patients had symptoms for 3 to 12 months. The various forms of modalities used for pain control in these patients, and their response is shown in tables. Of the patients, $84 \%$ were operated by the neurosurgeons and the rest by orthopedic surgeons. Of our patients, $88 \%$ were operated at single level and rest at multiple levels. Of patients, $60 \%$ had disk prolapse at L4-5 level and 44\% at L5S1. Forty-two patients did not show improvement or expressed worsening of their symptoms after surgery giving $8 \%$ incidence of FDS. Of these, $26(5 \%)$ had to be reoperated, and their symptoms started to improve slowly. The rest of patients were managed conservatively, and these also showed some improvement with time. Patients were observed for mean duration of 48 weeks.

\subsection{Results of FIS-based predictions}

The FIS classification was able to correctly identify 37 of the eventual 42 patients who had FDS, as high risk, that is, true-positives. Five patients who eventually had FDS were not identified by FIS and were incorrectly classified as low risk, that is, false-negatives. Of the 459 patients who eventually had good surgical outcomes, 394 were correctly identified by FIS as low risk, that is, true-negative. Of these 459 patients, 65 were incorrectly identified by FIS as high risk, that is, false-positive. By standard statistical formulas, we can therefore calculate that FIS has a sensitivity of $88 \%$ and specificity of $86 \%$ in the prediction of patients most likely to have poor outcome after lumbosacral miscrodiskectomy. The test thus has a positive predictive value of 0.36 and a negative predictive value of 0.98 (Table 3 ).

\section{Discussion}

Fuzzy inference system has been developed using Matlab's Fuzzy Logic tool box. The idea of Fuzzy Logic was introduced by an engineer and systems scientist Lotfi Zadeh [64] almost 4 decades ago and has grown in popularity in academic as well as research communities since then. Its introduction to medicine is difficult to trace; however, a review published 5 years back showed an increase in Fuzzy Logic-related medical publications from just 2 to 175, for 10 years [59]. A search generated on Medline at the time of writing this article using "Fuzzy
Logic" as keywords reveals more than 1600 search results. Sproule et al [58] defined Fuzzy Logic as "the science of reasoning, thinking, and inference that recognizes and uses the real world phenomenon that everything is a matter of degree." It may be considered an extension of binary logic theory that does not require crisp definitions and distinctions. Previously all medical data were analyzed using probabilitybased statistical methods that invariably worked on the principles of yes-no, have-have not, true-false, or blackwhite. These are based on the Aristotelian logic of the excluded middle. Real life in general and medicine in particular has very little that can be classified as entirely black and white, mostly it is gray, and that too in its varying shades [35]. The Bayesian statistics approach or the basis of Fuzzy Logic holds that "contingent probability" or "plausibility" that involves recognition of intermediate logical values is more appropriate to medical science.

Fuzzy Logic associates degrees of memberships to the values within a subset of likely possibilities instead of a hard yes-no type decision and then uses this concept in a computationally effective manner. Adapting from an example given by Torres and Nieto [59] using the definition of health, if we state that a person is healthy, does having a broken nail make this statement true, and would it be false if he had terminal cancer? Everybody is healthy to some degree "h" and ill to some degree "i." So if the person is totally healthy, $\mathrm{h}=1$ and $\mathrm{i}=0$, this would be Aristotelian logic, but Fuzzy Logic would introduce further subdivisions such as if the person is ill, $h<0$ and $i>0$. In different situations, if the patient is dead, $\mathrm{h}=0$ and $\mathrm{i}=1$; in case of an inoperable advanced high-grade glioma, $h=0.05$ and $i=0.95$; in case of an acute subdural hematoma, $\mathrm{h}=0.4$ and $\mathrm{i}=0.6$; and in case of a broken nail only, $h=0.999$ and $i=0.001$. Instead of assuming that everything must be defined crisply into black and white that is the binary view, the fuzzy view holds that most things in the world fall somewhere in between black and white, that is in varying shades of gray, and should be analyzed as such. So any diagnosis, with perhaps the exception of "death," is not absolute and can be expressed within a probability between 0 and 1 , that is, between certainly present and certainly absent. Therefore, a patient with 0.2 is more likely not to have the disease and another with 0.9 is more likely to have the disease and similarly a patient with 0.7 is also likely to have the disease but not as much as the patient with 0.9. Such an approach seems more suited to the medical profession. Interestingly, the human 
brain operates on similar principle. For instance, the understanding of coffee temperature by a human observer could be described by degrees such a "cold," "warm," "hot," "normal," or even to such extent as "slightly hotter than warm yet slightly cooler than hot," something that the computer operating upon binary principles would not understand unless expressed in exact numeric values. Grossi [18] has also expressed another interesting concept and points out the distinction between Fuzzy Logic and probability. Both operate over the same numeric range, for example, 0.0 representing false and 1.0 representing true, at the 2 extremes; however, the difference in interpretation is significant. If applied to a person's age for instance, a value of 8.0 from the probabilistic approach would translate as an $80 \%$ chance of a person being old, whereas the fuzzy terminology would mean the person's degree of membership within the set of old people is 0.80 . In nonmathematical terms, the first view supposes that the person is or is not old; it is just that we only have an $80 \%$ chance of knowing which set he is in. By contrast, fuzzy terminology supposes that person is "more or less" old, and in the specific example, the "fuzzy degree" of membership corresponds to the value of 0.80 .

We used Fuzzy Logic for the prediction of outcomes in patients undergoing lumbar microdiskectomy. Besides being used by a number of medical researchers, Fuzzy Logic has also been used specifically for prediction of outcomes $[19,35,46,59]$. It was found to be superior to logistic regression and classification trees in the prediction of lymph node metastasis in carcinoma tongue [51] and was also found to be sensitive in the prediction of postoperative infection after gastric cancer surgery; detection and progression in visceral malignancies [30,50]; prediction of morbidity after lung resection [48]; in breast and prostate cancer [52]; prediction of bleeding after ear, nose, and throat procedures [44]; and others. The first mention of Fuzzy Logic in neurosurgical text was in Surgical Neurology in 2001 by Jobe et al [23] in an article that was preceded by a full page of author's introductory note. Today, it is being applied in various neuroscience-related areas with good results. It is being used in the neurosurgical intensive care $[22,47,55]$, for brain and lesion volume estimation $[6,39,45]$, interpretation of functional magnetic resonance imaging [36], for diagnosing glial tumors [5], for planning of deep brain stimulation [62], in visualizing nerve fibers in the human brain [2], while studying chronic spinal cord injury [17], stroke [14,20,21,24], scoliosis surgery [40], and in planning radiation therapy [43].

Microdiskectomy for intervertebral disk herniations is among the commonest neurosurgical procedures with good to excellent outcomes reported in up to $90 \%$ of patients; however, it has also been reported that up to $20 \%$ to $40 \%$ patients continue to have their preoperative symptoms $[1,4,8,10,15,16,28,33,34,57,63]$. It is this group of patients who fail to improve after surgery that have aroused researchers and are also the subject of our research. Various prognostic indicators have been suggested to identify these patients preoperatively, which include duration of symptoms [41,42], smoking [13], duration of sick leave [56], preoperative functional status [56], lack of physical exercise [29], lifestyle [13], Lesegue sign [32], psychologic or behavioral factors $[12,25,26,29,37,38,49,60,61]$, type of herniations [7,8,13,31], postoperative SLR [27], and intraoperative complications [3], among others. Most of these researchers have used multivariate logistic regression analysis, which on the basis of retrospective or prospective data is able to identify 1 or 2 predictive indicators; as a result, it has limited clinical applications. We believe that the multivariate logistic regression is inferior to Fuzzy Logic as although it does incorporate all the positive causal relationships, it fails to incorporate the negative causal relationships in the final analysis. Fuzzy Logic incorporates all of this information as well as the positive predictors suggested by human heuristics into formal rule bases that analyzes the data as such. The multivariate is also limited by its inability to analyze the degree of causal relationships, which is the essence of using the FIS. We have used the FIS applying it on a large number of patients and including most of the previously identified risk factors as well as those that we thought would predict the outcome and are reporting $88 \%$ sensitivity and $86 \%$ specificity, which is comparable to other multivariate done previously. According to our results, FIS generally overestimated the high-risk patients that, in our opinion, are preferable to underestimation. An overestimation of high-risk patients is acceptable in case of a benign disease such as disk prolapse where nonoperative management and close observation are practical options with little risk. Such an overestimation may not be acceptable in case of a more sinister surgical pathologic condition, where delay in surgery poses high risks of dire consequences.

The selection of input memberships also merits some discussion. Some of the variables are known predictors of FDS, but others have been short-listed entirely upon the coinvestigator's personal experience. For example, even if most published articles have not shown patients' gender or preoperative use of oral steroids to be a predictor of FDS, but the coinvestigator "thinks" they may be important factors, these are selected. On the other hand, if a certain population does not have litigation-related issues, there is no point in including them in the input memberships regardless of what the literature suggests. This may seem contrary to the principles of evidence-based medicine, but 4 decades of experience with Fuzzy Logic has proven that the mathematics actually works. In fact, such a selection process turns out to be superior to conventional methods as it also incorporates variables specific to a certain population, instead of blindly following literature published after analyzing patient populations dissimilar to one's own.

It may also be argued that the current analysis was done on one clinician's heuristics, and perhaps the results may be better if another more experienced clinician was to select input memberships. We believe that seasoned clinicians are likely to select mostly similar input memberships - those 
that are either proven by literature or are generally known to be predictors of FDS. The difference in input memberships would be only those related to their cultural specificities. The mathematics of Fuzzy Logic is such that dissimilar input memberships that are not clinically significant would not alter the sensitivity of the test, for a given population, but would give different results if applied to different populations with variable demographics. This is also evident as most clinical studies have suggested different predictors of FDS, suggesting that there may be some cultural variation to this factor; therefore, in our opinion, including input memberships based on a clinician's personal experience with that specific population to the already known predictors adds to the sensitivity of the test for that patient population. One set of input memberships cannot be standardized for different patient populations with their own cultural heterogeneities. On the other hand, if our input memberships were to be applied on the data of another center within our own city, it is likely to express exact results.

We believe that the mathematics can be used during outpatient consultations to aid in decision making. The procedure is extremely simple, and all that the clinician is required to do is to select the variables for a particular patient from an available list on a computer-based program. The software that already has previously stored input memberships for that specific population runs the selected variables and comes up with the statistics within seconds. Such a methodology has an added advantage that even residents and junior clinicians can independently make decisions, based essentially on senior clinician's experience and are just as precise. We would add that this only adds to the clinical judgment and unless validated to be a hundred percent sensitive and specific for a certain population can give erroneous results - $\mathrm{a}$ weakness common to almost every diagnostic test known to man.

There are a few weaknesses of our study. One is that the data were retrospectively collected, and although the introduction of thorough clinical pathways has resulted in detailed patient information, we were still not able evaluate certain variables recently shown to affect outcome such as annular competence [7]. We also did not get a formal psychologic workup of our patients unless indicated by a suggestive history. This has been suggested by a few authors but to us seems overinvestigating our patients. We offer surgical decompression in the presence of convincing history, physical findings, radiologic evidence, and failure to improve after a trial of 8 weeks of conservative management. Secondly, psychosocial, litigation, and workman's compensation issues have much less significance in our country and therefore unlikely to influence outcomes in our patients and hence did not appear to be a likely predictor of FDS in our experience. There are also a few other cultural dissimilarities between our patient population and that reported in most published literature. One is the higher proportion of male patients that is not unusual as a lot of reported literature from our country has shown a male predominance even in diseases not known to have sex preferences. This has been previously explained on the presumption that the male in our society are more likely to seek medical attention as compared to females who mostly stay at home $[9,53,54]$. The other difference is the high mean body mass index that is unusual as the study comes from an underprivileged country. We do not recommend that our rule bases be applied on other patient populations unless validated by their own dataset, rule bases, and outcomes.

\section{Conclusion}

Fuzzy inference system is a sensitive method of predicting patients who will fail to improve with surgical intervention. We have used the FIS applying it on a large number of patients and including most of the previously identified risk factors as well as those that we thought would predict the outcome. Our study suggests that FIS has $88 \%$ sensitivity and $86 \%$ specificity in the prediction of patients likely to have poor outcomes after disk surgery. Although we have used a fairly large patient population, the results are based on our own dataset and because of slight demographic differences may only apply to our population unless validated by other centers.

\section{References}

[1] Andrews DW, Lavyne MH. Retrospective analysis of microsurgical and standard lumbar discectomy. Spine 1990;15:329-35.

[2] Axer H, Jantzen J, Keyserlingk DG, Berks G. The application of fuzzybased methods to central nerve fiber imaging. Artif Intell Med 2003;29 (3):225-39.

[3] Barrios C, Ahmed M, Arrotegui JI, Björnsson A. Clinical factors predicting outcome after surgery for herniated lumbar disc: an epidemiological multivariate analysis. J Spinal Disord 1990;3(3): 205-9.

[4] Barrios C, Ahmed M, Arrotegui J, Bjornsson A, Gillstrom P. Microsurgical versus standard removal of herniated lumbar disc. A 3-year comparison in 150 cases. Acta Orthop Scand 1990;61:399-403.

[5] Belacel N, Boulassel MR. Multicriteria fuzzy classification procedure PROCFTN: methodology and medical application. Fuzzy Sets Syst 2004;141(2):203-17.

[6] Brandt ME, Bohan TP, Kramer LA, Fletcher JM. Estimation of CSF, white and gray matter volumes in hydrocephalic children using fuzzy clustering of MR images. Comput Med Imaging Graph 1994;18(1): 25-34.

[7] Carragee EJ, Han MY, Suen PW, Kim D. Clinical outcomes after lumbar discectomy for sciatica: the effects of fragment type and anular competence. J Bone Joint Surg Am 2003;85-A(1):102-8.

[8] Carragee EJ, Kim DHA. Prospective analysis of magnetic resonance imaging findings in patients with sciatica and lumbar disk herniation. Correlation of outcomes with disc fragment and canal morphology. Spine 1997;22:1650-60.

[9] Chandana A, Islam N, Jabbar A, Zuberi L, Haque N. Clinical features and outcome of surgery in 30 patients with Acromegaly. J Pak Med Assoc 2004;54(6):315-9.

[10] Davis RA. Long-term outcome analysis of 984 surgically treated herniated lumbar discs. J Neurosurg 1994;80:415-21.

[11] den Boer JJ, Oostendorp RA, Beems T, Munneke M, Evers AW. Continued disability and pain after lumbar disc surgery: the role of cognitive-behavioral factors. Pain 2006;123(1-2):45-52. 
[12] den Boer JJ, Oostendorp RA, Beems T, Munneke M, Oerlemans M, Evers AW. A systematic review of bio-psychosocial risk factors for an unfavourable outcome after lumbar disc surgery. Eur Spine J 2006;15 (5):527-36.

[13] Dewing CB, Provencher MT, Riffenburgh RH, Kerr S, Manos RE. The outcomes of lumbar microdiscectomy in a young, active population: correlation by herniation type and level. Spine 2008;33(1):33-8.

[14] Dickerson JA, Helgason CM. The characterization of stroke subtype and science of evidence-based medicine using Fuzzy Logic. J Neurovasc Dis 1997;2(4):138-44.

[15] Dvorak J, Gauchat MH, Valach L. The outcome of surgery for lumbar disc herniation. A 4-17 years' follow-up with emphasis on somatic aspects. Spine 1988;13:1418-22.

[16] Eismont FJ, Currier B. Surgical management of lumbar intervertebraldisc disease. J Bone Joint Surg Am 1989;71:1266-71.

[17] Ellingson BM, Ulmer JL, Prost RW, Schmit BD. Morphology and morphometry in chronic spinal cord injury assessed using diffusion tensor imaging and fuzzy logic. Conf Proc IEEE Eng Med Biol Soc 2006;1:1885-8.

[18] Grossi E. Medical concepts related to individual risk are better explained with "plausibility" rather than "probability. BMC Cardiovasc Disord 2005;5:31.

[19] Hanai T, Honda H. Application of knowledge information processing methods to biochemical engineering, biomedical, and bioinformatics fields. Adv Biochem Eng Biotechnol 2004;91:51-73.

[20] Helgason CM, Jobe TH. Causal interactions, fuzzy sets and cerebrovascular "accident": the limits of evidence-based medicine and the advent of complexity-based medicine. Neuroepidemiology 1999;18(2):64-74.

[21] Helgason CM, Malik DS, Cheng SC, Jobe TH, Mordeson JN. Statistical versus fuzzy measures of variable interaction in patients with stroke. Neuroepidemiology 2001;20(2):77-84.

[22] Huang SJ, Shieh JS, Fu M, Kao MC. Fuzzy logic control for intracranial pressure via continuous propofol sedation in a neurosurgical intensive care unit. Med Eng Phys 2006;28(7):639-47.

[23] Jobe TH, Helgason CM, Roitberg BZ. "Show me the numbers": the application of numbers to medical science. Surg Neurol 2001;56(1): 3-7.

[24] Jobe TH, Helgason CM. The fuzzy cube and causal efficacy: representation of concomitant mechanisms in stroke. Neural Networks 1998;11(3):549-55.

[25] Junge A, Fröhlich M, Ahrens S, Hasenbring M, Sandler A, Grob D, Dvorák J. Predictors of bad and good outcome of lumbar spine surgery. A prospective clinical study with 2 years' follow up. Spine 1996;21(9): 1056-64.

[26] Junge A, Dvorak J, Ahrens S. Predictors of bad and good outcomes of lumbar disc surgery. A prospective clinical study with recommendations for screening to avoid bad outcomes. Spine 1995;20(4):460-8.

[27] Jönsson B, Strömqvist B. Significance of a persistent positive straight leg raising test after lumbar disc surgery. J Neurosurg 1999;91(1 Suppl):50-3

[28] Kahanovitz N, Viola K, McCulloch J. Limited surgical discectomy and microdiscectomy. A clinical comparison. Spine 1989;14:79-81.

[29] Kara B, Tulum Z, Acar U. Functional results and the risk factors of reoperations after lumbar disc surgery. Eur Spine J 2005;14(1):43-8.

[30] Keller T, Bitterlich N, Hilfenhaus S, Bigl H, Löser T, Leonhardt P. Tumour markers in the diagnosis of bronchial carcinoma: new options using Fuzzy Logic-based tumour marker profiles. J Cancer Res Clin Oncol 1998;124(10):565-74.

[31] Knop-Jergas BM, Zucherman JF, Hsu KY, DeLong B. Anatomic position of a herniated nucleus pulposus predicts the outcome of lumbar discectomy. J Spinal Disord 1996;9(3):246-50.

[32] Kohlboeck G, Greimel KV, Piotrowski WP, Leibetseder M, Krombholz-Reindl M, Neuhofer R, Schmid A, Klinger R. Prognosis of multifactorial outcome in lumbar discectomy: a prospective longitudinal study investigating patients with disc prolapse. Clin J Pain 2004;20(6):455-61.
[33] Kotilainen E, Valtonen S. Clinical instability of the lumbar spine after microdiscectomy. Acta Neurochir (Wien) 1993;125:120-6.

[34] Lewis PJ, Weir BKA, Broad RW, Grace MG. Long term prospective study of lumbosacral discectomy. J Neurosurg 1987;67:49-53.

[35] Licata G. Probabilistic and fuzzy logic in clinical diagnosis. Intern Emerg Med 2007;2(2):100-6.

[36] Lu Y, Jiang T, Zang Y. Region growing method for the analysis of functional MRI data. Neuro Image 2003;20(1):455-65.

[37] Main CJ, Wood PL, Hollis S, Spanswick CC, Waddell G. The Distress and Risk Assessment Method. A simple patient classification to identify distress and evaluate the risk of poor outcome. Spine 1992;17 (1):42-52.

[38] Mannion AF, Elfering A, Staerkle R, Junge A, Grob D, Dvorak J, Jacobshagen N, Semmer NK, Boos N. Predictors of multidimensional outcome after spinal surgery. Eur Spine J 2007;16(6):777-86.

[39] Moonis G, Liu J, Udupa JK, Hackney DB. Estimation of tumor volume with fuzzy-connectedness segmentation of MR images. AJNR Am J Neuroradiol 2002;23(3):356-63.

[40] Nault ML, Labelle H, Aubin CE, Balazinski M. The use of fuzzy logic to select which curves need to be instrumented and fused in adolescent idiopathic scoliosis: a feasibility study. J Spinal Disord Tech 2007;20 (8):594-603.

[41] Nygaard OP, Kloster R, Solberg T. Duration of leg pain as a predictor of outcome after surgery for lumbar disc herniation: a prospective cohort study with 1-year follow up. J Neurosurg 2000;92(2 Suppl):131-4.

[42] Nygaard OP, Romner B, Trumpy JH. Duration of symptoms as a predictor of outcome after lumbar disc surgery. Acta Neurochir (Wien) 1994;128(1-4):53-6.

[43] Papageorgiou EI, Stylios CD, Groumpos PP. An integrated two-level hierarchical system for decision making in radiation therapy based on fuzzy cognitive maps. IEEE Trans Biomed Eng 2003;50(12):1326-39.

[44] Pizzi NJ. Bleeding predisposition assessments in tonsillectomy/ adenoidectomy patients using fuzzy interquartile encoded neural networks. Artif Intell Med 2001;21(1-3):65-90.

[45] Liu J, Udupa JK, Odhner D, Hackney D, Moonis G. A system for brain tumor volume estimation via MR imaging and fuzzy connectedness. Comput Med Imaging Graph 2005;29(1):21-34.

[46] Ramesh AN, Kambhampati C, Monson JR, Drew PJ. Artificial intelligence in medicine. Ann R Coll Surg Engl 2004;86(5):334-8.

[47] Roitberg B. Research news and notes. Surg Neurol 2008;69(5):439-40.

[48] Sakaguchi S, Takifuji K, Arita S, Yamaue H. Development of an early diagnostic system using fuzzy theory for postoperative infections in patients with gastric cancer. Dig Surg 2004;21(3):210-4.

[49] Schade V, Semmer N, Main CJ, Hora J, Boos N. The impact of clinical, morphological, psychosocial and work-related factors on the outcome of lumbar discectomy. Pain 1999;80(1-2):239-49.

[50] Schneider J, Bitterlich N, Velcovsky HG, Morr H, Katz N, Eigenbrodt E. Fuzzy logic-based tumor-marker profiles improved sensitivity in the diagnosis of lung cancer. Int J Clin Oncol 2002;7(3):145-51.

[51] Schwarzer G, Nagata T, Mattern D, Schmelzeisen R, Schumacher M. Comparison of fuzzy inference, logistic regression, and classification trees (CART). Prediction of cervical lymph node metastasis in carcinoma of the tongue. Methods Inf Med 2003;42(5):572-7.

[52] Seker H, Odetayo MO, Petrovic D, Naguib RN, Bartoli C, Alasio L, Lakshmi MS, Sherbet GV. Assessment of nodal involvement and survival analysis in breast cancer patients using image cytometric data: statistical, neural network and fuzzy approaches. Anticancer Res 2002; 22(1A):433-8.

[53] Shamim SM, Hameed K. Surgically treated rectal prolapse: experience at a teaching hospital. J Pak Med Assoc 2005;55(6):247-50.

[54] Shamim MS, Bari ME, Khursheed SF, Jooma R, Enam SA. Pituitary adenomas: demographic differences and surgical outcomes in a South Asian country. Can J Neurol Sci 2008;35(2):198-203.

[55] Shieh JS, Fu M, Huang SJ, Kao MC. Comparison of the applicability of rule-based and self-organizing fuzzy logic controllers for sedation control of intracranial pressure pattern in a neurosurgical intensive care unit. IEEE Trans Biomed Eng 2006;53(8):1700-5. 
[56] Solberg TK, Nygaard OP, Sjaavik K, Hofoss D, Ingebrigtsen T. The risk of "getting worse" after lumbar microdiscectomy. Eur Spine J 2005;14(1):49-54.

[57] Spengler DM, Ouellette EA, Battie M, Zeh J. Elective discectomy for herniations of a lumbar disc. Additional experience with an objective method. J Bone Joint Surg Am 1990;72:230-7.

[58] Sproule BA, Naranjo CA, Türksen IB. Fuzzy pharmacology: theory and applications. Trends Pharmacol Sci 2002;23(9):412-7.

[59] Torres A, Nieto JJ. Fuzzy Logic in medicine and bioinformatics. J Biomed Biotechnol 2006;2006(2):1-7.

[60] Trief PM, Grant W, Fredrickson B. A prospective study of psychological predictors of lumbar surgery outcome. Spine 2000;25 (20):2616-21.

[61] Schofferman J, Reynolds J, Herzog R, Covington E, Dreyfuss P, O'Neill C. Failed back surgery: etiology and diagnostic evaluation. Spine J 2003;3(5):400-3.

[62] Villéger A, Ouchchane L, Lemaire JJ, Boire JY. Assistance to planning in deep brain stimulation: data fusion method for locating anatomical targets in MRI. Conf Proc IEEE Eng Med Biol Soc 2006;1:144-7.

[63] Weber H. Lumbar disc herniation. A controlled, prospective study with ten years of observation. Spine 1983;8:131-40.

[64] Zadeh L. Fuzzy sets. Inf Control 1965;8:338-53.

\section{Commentary}

The authors have presented an interesting clinical application of Fuzzy Logic to the problem of selecting patients for lumbar diskectomy. Although the method cannot substitute for clinical judgment, it certainly can be used as a tool for teaching residents and junior surgeons how to select patients. The use of Fuzzy Logic in other clinical problems has been well discussed by the authors, and they present a good simplification of the mathematics that most clinicians likely can appreciate.

I would encourage the authors to continue to improve their technique and to use it to help understand why some clinicians are better judges of potential outcome than others.

Phillip Dickey, MD Yale School of Medicine New Haven, Conn 06510 